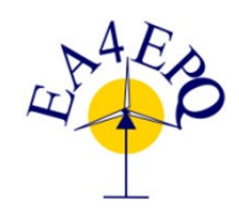

$18^{\text {th }}$ International Conference on Renewable Energies and Power Quality (ICREPQ'20)

Granada (Spain), $1^{\text {st }}$ to $2^{\text {nd }}$ April 2020

Renewable EEnergy and Pourer Quality. Fournal (RE\&PQJ)

ISSN 2172-038 X, Volume No.18, June 2020

\title{
Multi-Input Boost Converter for Parallel Connected Renewable Energy Systems
}

\author{
R.H.M.Ali ${ }^{1}$, K.A.Khan ${ }^{2}$, M.Khalid ${ }^{2}$, and A.A.Khan ${ }^{3}$ \\ ${ }^{1}$ Department of Electrical Engineering \\ Aligarh Muslim University \\ Aligarh 202002, India \\ Email: raohasanainmuzaffar@gmail.com \\ ${ }^{2}$ Department of Electrical Engineering \\ King Fahd University of Petroleum and Minerals (KFUPM) \\ Dhahran 31261, Kingdom of Saudi Arabia \\ Email: g201604320@kfupm.edu.sa, mkhalid@kfupm.edu.sa \\ ${ }^{3}$ Telecom Engineering and Substation Automation Department (TESAD), Saudi Electric Company (SEC) \\ Riyadh 13241, Kingdom of Saudi Arabia \\ Email: aakhan2@se.com.sa
}

\begin{abstract}
This paper proposes a multi-input boost converter for parallel connected renewable energy systems. The proposed converter simultaneously harnesses power from two parallel connected renewable energy sources while maintaining constant output voltage. The operation of the converter is examined and its operating modes are developed. The small-signal ac model of the proposed converter is developed in continuous conduction mode by circuit averaging technique. Based on the developed small-signal ac model, line-to-output and control-tooutput transfer functions are derived and the relevant Bode plots are obtained analytically and are verified by circuit simulation for evaluating open-loop and closed-loop stability of the converter. The analytical results are in good agreement with the computer results, validating the developed small-signal ac model and the derived transfer functions.
\end{abstract}

Index Terms-Constant voltage controller, hybrid renewable energy systems, multi-input converter, small-signal analysis.

\section{INTRODUCTION}

Power industries were built on the foundations of conventional sources of energy (fossil fuels, hydro, nuclear, etc). However, the combination of ever-increasing electric power demand, limited carbon based resources and environmental concerns, the need for alternate sources of energy has emerged recently. [1], [2]. Renewable energy sources are advantageous over conventional sources, nevertheless they are highly intermittent in nature. However, hybrid power sources proves to establish a continuous power supply with certain comple- mentary RESs (solar and wind) [3] . Different combinations of renewable and conventional energy sources with power electronic interfacing have been suggested to overcome the limitations of isolated energy sources. The objective of the power electronic interface is to harness maximum power from RES sources and in accordance maintain the power quality of the grid network as well as obviate converter switching losses [4].

Integration of renewable with conventional energy system as proposed in [5], is a feasible solution to reduce emission and operational cost of distribution system particularly in remote areas. In literature, many control strategies with different types of DC-DC converters have been proposed for control and Maximum Power Point Tracking (MPPT) of a Hybrid Renewable Energy System (HRES) [6]-[8]. A novel method for integration of a four-level DC-DC converter with high frequency isolation transformer is proposed to connect the HRES to the grid [9]. Accordingly, introduction of DC bus being fed from HRES with bidirectional storage system have been implemented [10]-[12] analyzing these systems with fuzzy logic, perturb and observe (PO) and sliding mode technique (SMC) to facilitate smooth transition between autonomous and grid connected modes thereby, achieving DC bus voltage regulation.

Similarly, various multi-input topologies for boost and cuk converter have been proposed [13]-[17] for hybrid renewable energy sources. The research in [13], [14], studies differ- 


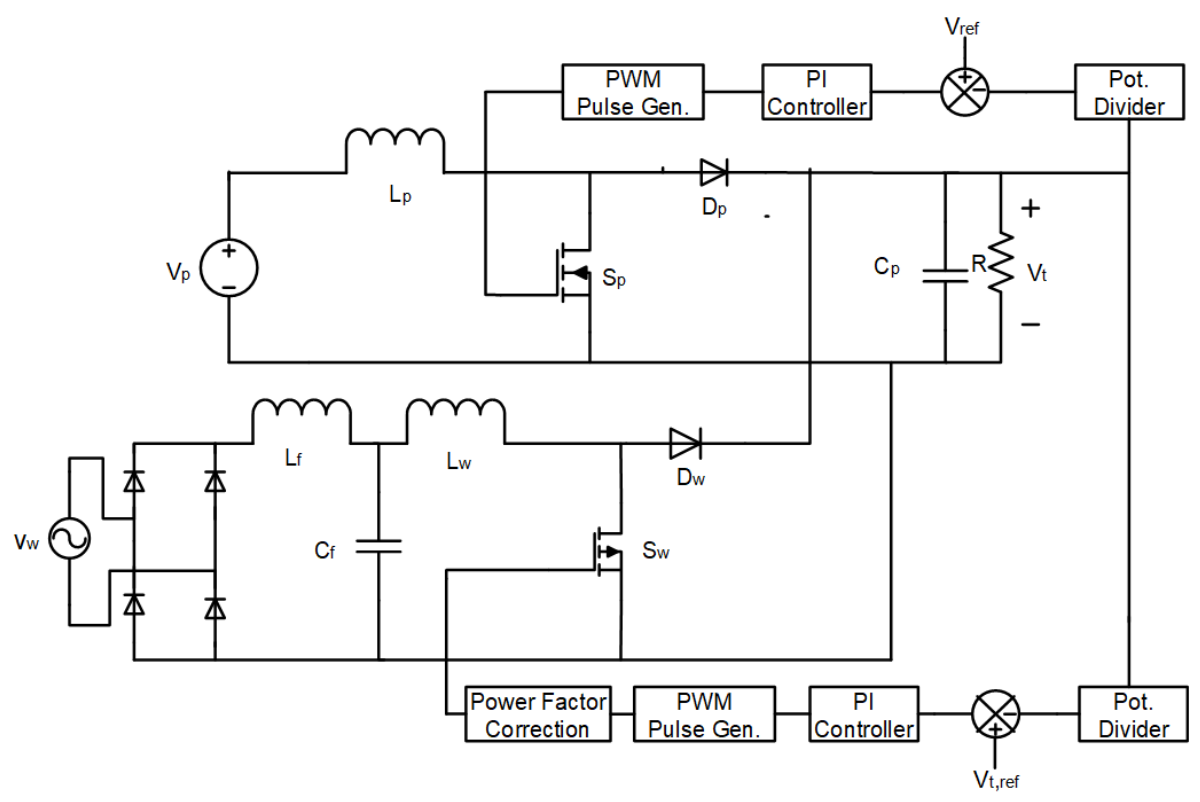

Fig. 1: Proposed topology of the hybrid renewable energy system.

ent modes of operations for a multi-input power converters (MIPC), incorporated in hybrid renewable energy sources (HRES). In [18], a cascaded topology of DC interface for numerous integration of distributed generation (DG) sources. This study proposes voltage control strategy for stable operation DG interconnections through DC-DC converter regulation and further obviates the requirement of complex communication server connections. Further, in [19] a novel integration of snubber cell is presented for boost converters to enhance zero voltage transition (ZVT). This novel integration ensures high step-up voltage and is able to operate under variable loading conditions and load distances. Furthermore, the study in [20] introduces a fractional order PID controller to overcome the limitations of H-bridge DC-DC converters such as, voltage overshoot and slow converter response. This control strategy additional supports smooth transition between continuous and discontinuous converter modes ensuring reduced energy losses.

The proposed topology is based on (i) flux additivity principle, (ii) pulse Width modulation choppers, and (iii) converter for energy storage elements; these topologies are exploited to supply domestic load requirements supplied with solar and wind RESs. A novel method for single-phase multilevel inverter is proposed in [21], this suggested an upper inverter fed from PV array and the lower inverter fed from wind turbine. The maximum power point tracking (MPPT) is based on sliding mode technique (SMC). From this method, improved efficiency and minimum voltage stress is achieved which was simulated and proved. Finally, for integration of sources having input and output current ripple (thermo-electric generator, wind, batteries, super capacitors), interleaved boost converters for high power applications are proposed in [22],
[23]. MPPT in these methods were obtained by perturb and observer algorithm and PWM technique and presented by simulation.

The remainder of this paper is organized as follows. Section II presents operation modes and control of the proposed converter strategy. Section III consists of the mathematical design and small signal analysis of the proposed grid network. The computational analysis and validation of proposed control strategy is presented in Section IV, followed by the conclusion in Section V.

\section{Proposed System Configuration}

The proposed parallel renewable energy sources based system is shown in Fig. 1. It comprises of two boost converters, one for each parallel connected renewable source. The upper converter is fed from PV module and the lower converter is fed from rectified wind turbine output voltage where upper boost converter is used to track the MPP of the PV module. Similarly, the MPP of the rectified output voltage from the wind turbine was simulated by lower boost converter with a pulse delay to create the complementary switching of the boost converters. The PWM technique allows to regulate the output voltage with a desired reference voltage.

\section{A. Operating Modes}

Any boost converter has two operating modes each corresponding to the state of switching device used (ON/OFF). Since, this system utilises complementary switching, the operation of the overall system is divided in two operating modes.

Mode $\mathbf{I}\left(0<\mathrm{t}<\mathrm{DT}_{s}\right)$

The switch $\mathrm{Sp}$ is $\mathrm{ON}$ and switch $\mathrm{Sw}$ is OFF. During this interval inductor current $i_{L p}$ flows through switch $\mathrm{Sp}$, which charges the inductor $i_{L p}$ with polarity and this current 


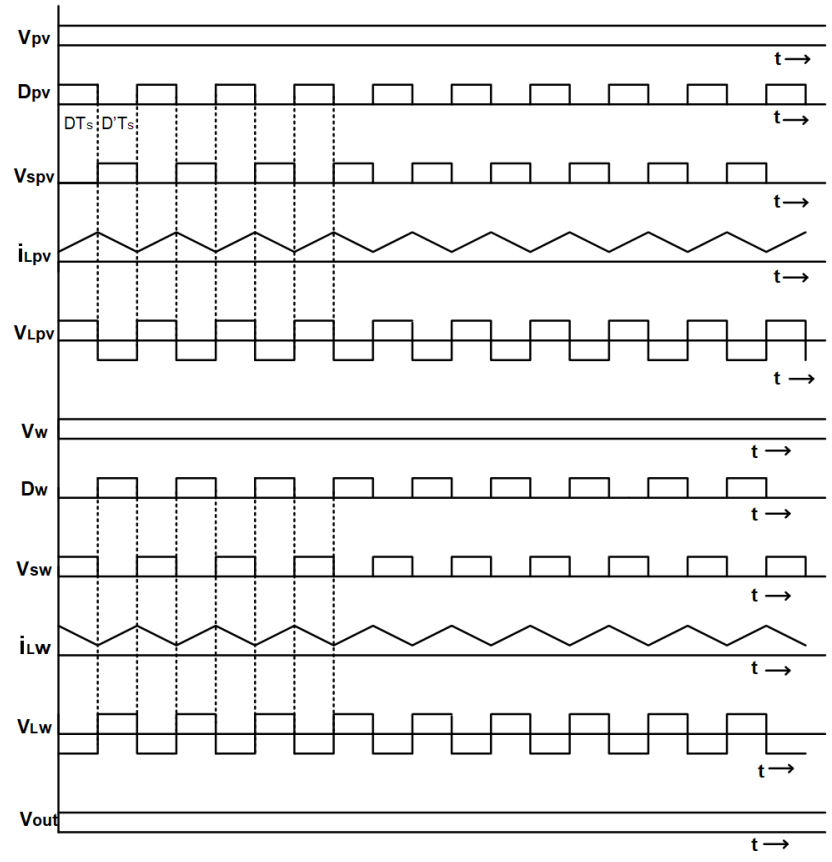

Fig. 2: Current and voltage waveshapes.

increases linearly with time as shown Fig. 2. Switch $S_{p}$ being in conducting state, the voltage $\left(V_{s p}\right)$ across it is zero, while inductor voltage $v_{L p}$ stays constant and equal to $V_{p}$. Since, the switch $S_{w}$ is OFF, inductor $L_{w}$ discharges linearly through diode $D_{w}$ with polarity, while inductor voltage $\left(v_{L w}\right)$ stays constant and equal to $V_{w}$. Power is transferred from second renewable energy source to the load.

Mode II $\left(\mathrm{DT}<\mathrm{t}<\mathrm{T}_{s}\right)$
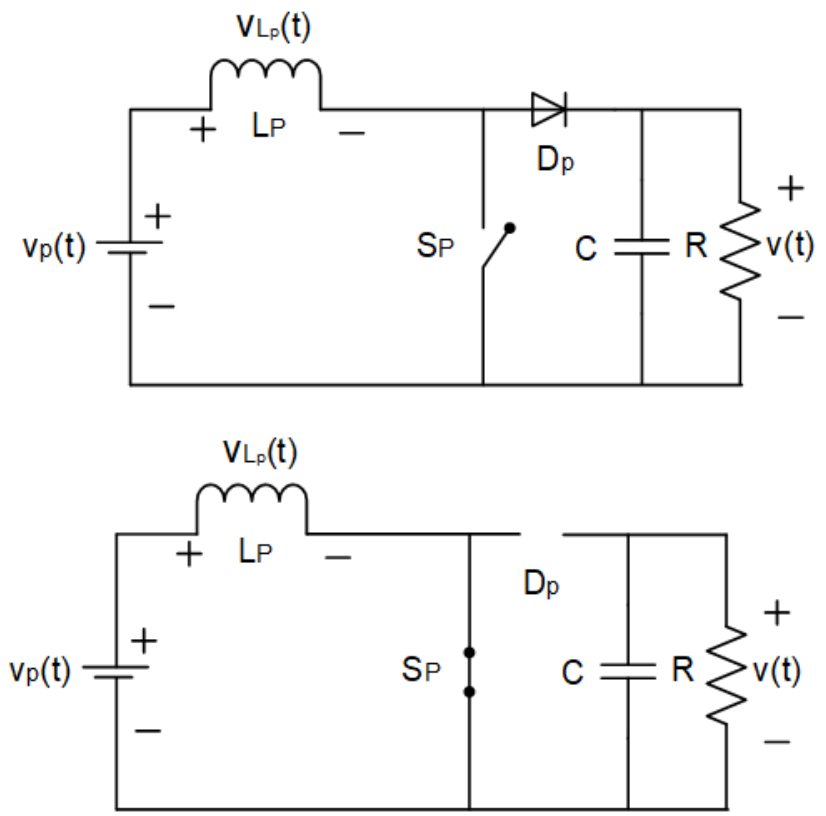

Fig. 3: Small Signal model of the converter.

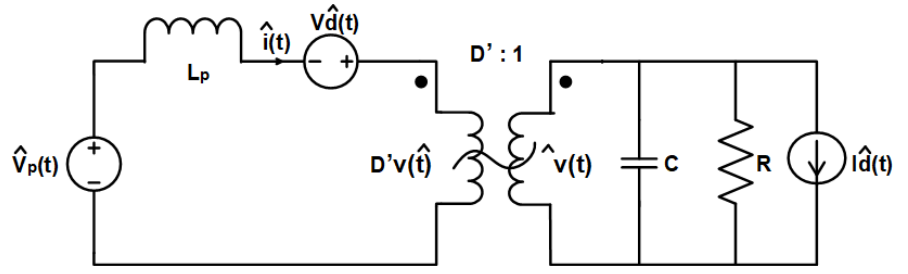

Fig. 4: Open loop small signal model of solar PV.

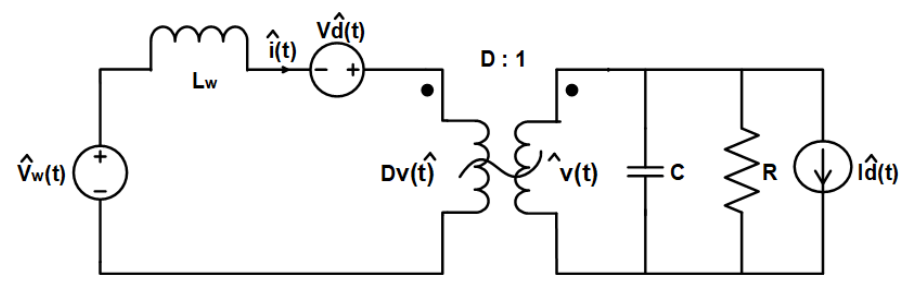

Fig. 5: Open loop small signal model of wind turbine generators.

During this period switch $S_{p}$ is $\mathrm{OFF}$ and $S_{w}$ is ON. Inductor current $i_{L w}$ flows through switch $S_{w}$ that charges the inductor $L_{w}$ with polarity and this current increases linearly with time. Switch $S_{p}$ being in conducting state, the voltage $\left(V_{s w}\right)$ across it is zero. While inductor voltage $v_{L w}$ stays constant and equal to $V_{w}$. Since the switch $\mathrm{Sp}$ is OFF, inductor $L_{w}$ discharges linearly through diode $D_{p}$ with polarity (Fig. 2). While the inductor voltage $\left(v_{L p}\right)$ stays constant and equal to $V_{p v}$. Power is transferred from first renewable energy source to the load. During both the operating modes, output voltage is sensed and then compared with the desired output voltage to generate an error signal, which is then integrated and fed to the PWM generator, hence adjusting the duty cycle to minimise the error signal to achieve the desired reference voltage.

\section{SYSTEM FRAMEWORK AND MODELING}

The proposed system configuration consists of two boost converters, which operate in complementary manner. In order to determine the stability of the overall system, it is necessary to investigate the closed loop transfer function of the system. The study comprises of the derivation of a canonical model of each individual converter and then combining the results of both canonical models. The first step in order to achieve the canonical model of each converter is to develop the open loop small signal ac equivalent circuit.

\section{A. Open loop small signal ac equivalent circuit}

The small signal model of the converter is shown in Fig 3. Here, $V_{p}(t)$ is the voltage generated by $\mathrm{PV}$ and wind generators and $V(t)$ acquired output voltage. Switch $S_{p}$ remains ON for a period $\mathrm{DT}_{s}$ over a switching period Ts. Average voltage across inductor and the capacitor over the time period $T_{s}$ is given in eqs (1) and (2) respectively.

$$
L \frac{d \hat{i}(t)_{T_{s}}}{d t}=d(t) \hat{v_{p}}(t)_{T_{s}}+d^{\prime}(t)\left[\hat{v}_{p}(t)_{T_{s}}-\hat{v}(t)_{T_{s}}\right]
$$




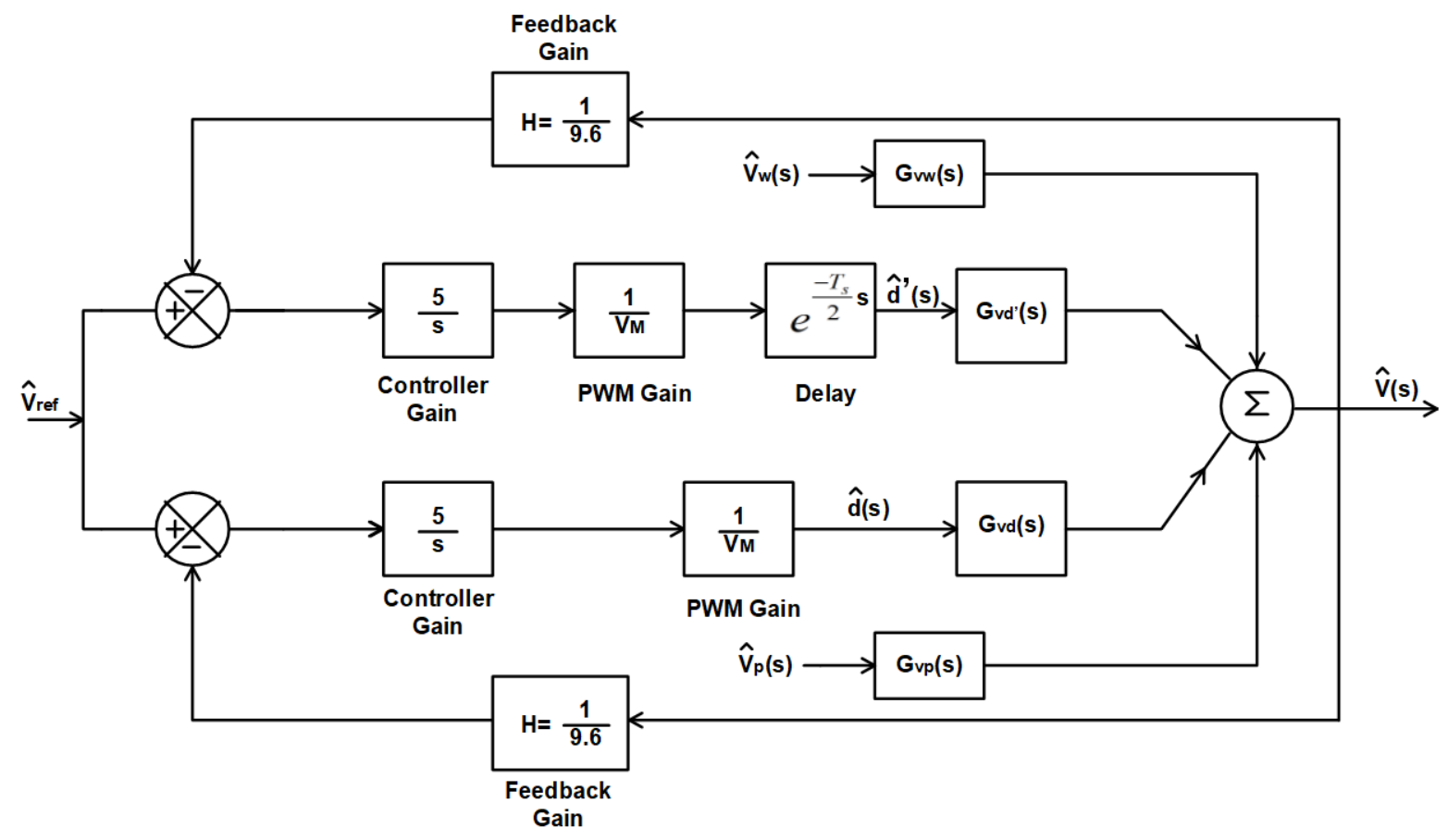

Fig. 6: Closed loop mathematical model of the proposed HRES.

$$
\hat{i_{c}}(t)_{T_{s}}=d(t)\left(\frac{-\hat{v}(t)_{T_{s}}}{R}\right)+d^{\prime}(t)\left[\hat{i}(t)_{T_{s}}-\frac{-\hat{v}(t)_{T_{s}}}{R}\right]
$$

Therefore, to obtain a small signal ac model let us assume that the input voltage and duty cycle are equal to some given (DC) quiescent values plus superimposed small ac variations in response and after any transient have subsided, the converter dependent voltages and currents will be equal to the corresponding quiescent values plus small ac variations as depicted in eq (3)

$$
\begin{array}{r}
\hat{v_{p}}(t)_{T_{s}}=V_{p}+\hat{v_{p}}(t) \\
d(t)=D+d(t) \\
\hat{i}(t)_{T_{s}}=I+\hat{i}(t) \\
\hat{v}(t)_{T_{s}}=V+\hat{v}(t)
\end{array}
$$

In addition, considering only the first order ac terms, the small signal analysis for the inductor and capacitor is termed further as follows:

$$
\begin{gathered}
\hat{v}_{p}(t)=L \frac{d \hat{i}(t)}{d t}+D^{\prime} \hat{v}(t)-V d(t) \\
C \frac{d \hat{v}(t)}{d t}=(D+d(t))\left[\frac{V+\hat{v}(t)}{R}\right]+D^{\prime}-d^{\prime}(t)\left[I=\hat{i}(t)-\frac{V+\hat{v}(t)}{R}\right] \\
D^{\prime} \hat{i}(t)=C \frac{d \hat{v}(t)}{d t}+\frac{\hat{v}(t)}{R}+I d(t)
\end{gathered}
$$

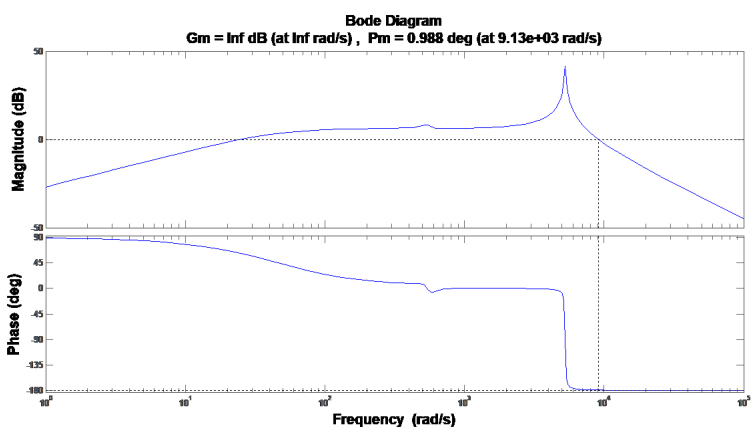

Fig. 7: Bode diagram for solar operation.

The small signal models obtained from the small signal modelling of the PV and wind systems is shown in Figs. 4 and 5 respectively.Accordingly, for the measurement of the

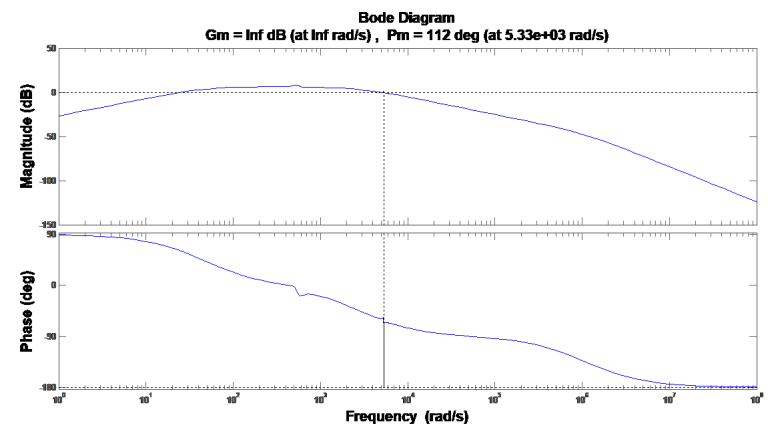

Fig. 8: Bode diagram for wind operation. 

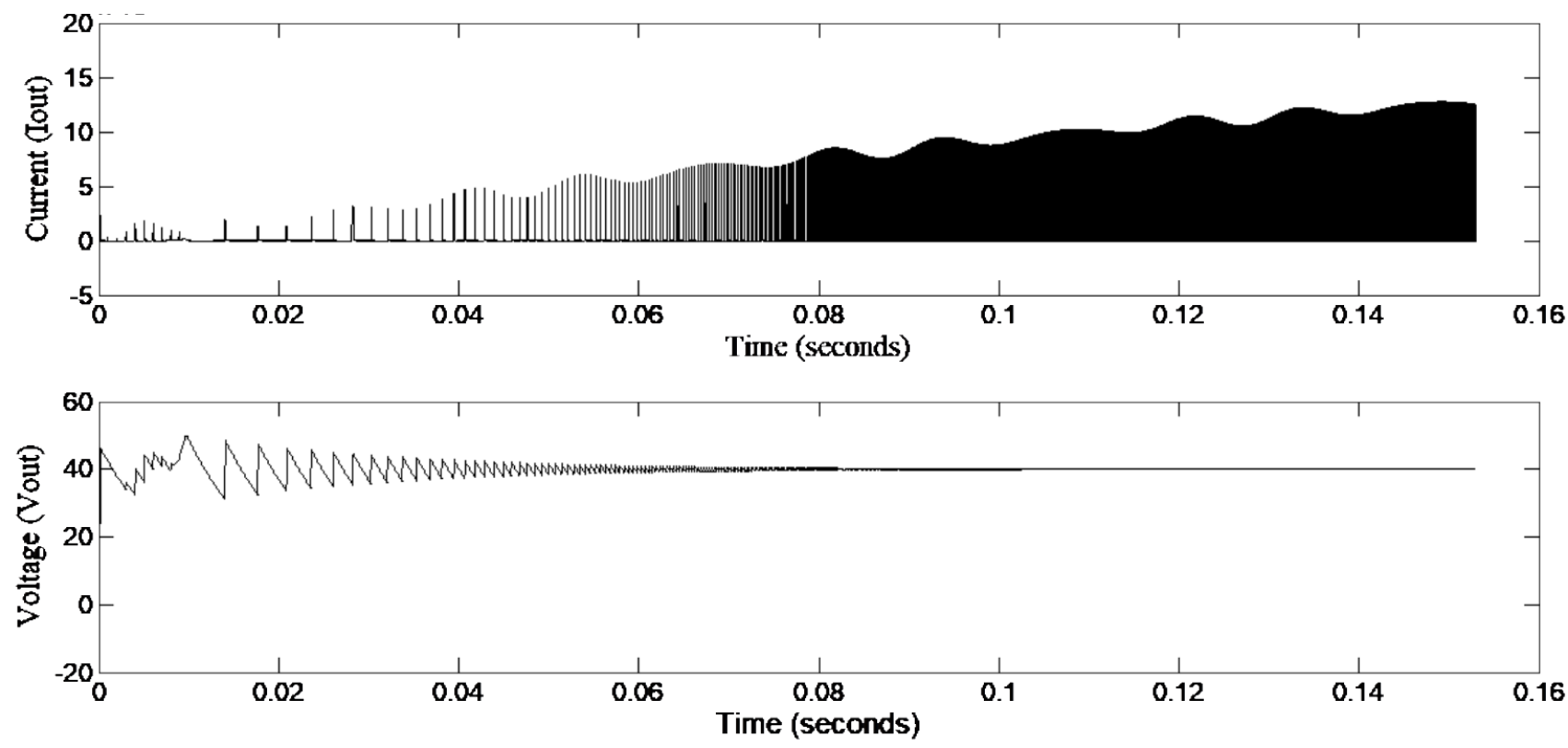

Fig. 9: Output current and voltage characteristics.

output fluctuations of the solar and wind generations a conical formulation is derived. Hence, the converter will have two inputs, i.e., control inputs $d(s)$ and line inputs $\hat{v}(s)$; one output component $\hat{v}(t)$ (7). In accordance, the open loop transfer function for solar PV and wind power generators and with their respective converters can be formulated as shown in eqs (8) and (9).

$$
\begin{aligned}
& \hat{v}(s)=G_{v d}(s) d(s)+G_{v p} \hat{v}_{p}(s) \\
& G_{v p}=\frac{1}{D^{\prime}} \frac{1}{1+\frac{s L_{p}}{R D^{\prime 2}}+\frac{s^{2} L_{p} C}{D^{\prime 2}}} \\
& G_{v w}=\frac{1}{D^{\prime}} \frac{1}{1+\frac{s L_{w}}{R D^{\prime 2}}+\frac{s^{2} L_{w} C}{D^{\prime 2}}}
\end{aligned}
$$

Where $\mathrm{Vw}(\mathrm{s})$ is the rectified voltage of wind turbine and duty cycle for this case will be $D^{\prime}$ owing to the complementary switching.

\section{B. Closed loop configuration}

The duty cycle cannot be expected to stay at a single value to give a constant output voltage under all conditions. In this front, the feedback provides a means to obtain a constant voltage by continuously monitoring it and after comparison with desired output voltage, the required adjustment in the duty cycle is made with the help of PWM controller. Thus, we can obtain specified output voltage with high accuracy, regardless of disturbances or component tolerances.

The mathematical block representation of the model is shown in Fig. 6, from which the output voltage is formulated

\begin{tabular}{|c|c|c|}
\hline Parameter & Symbol & Values \\
\hline Switching frequency & fs & $1000 \mathrm{~Hz}$ \\
\hline \multicolumn{3}{|c|}{ Wind turbine operating parameters) } \\
\hline Input AC voltage & $V_{w}$ & $25 \mathrm{~V}(\mathrm{rms})$ \\
\hline Diode & $D_{w}$ & $\begin{array}{c}\mathrm{R}=1 \mathrm{~m} \Omega \\
V_{f}=0.8 \mathrm{~V} \\
R_{s}=500 \Omega \\
C_{s}=250 \mathrm{nF}\end{array}$ \\
\hline Filter inductance & $L_{f}$ & $9 \mathrm{mH}$ \\
\hline Filter capacitance & $C_{f}$ & $1000 \mu \mathrm{F}$ \\
\hline \multicolumn{3}{|c|}{ Solar PV operating parameters) } \\
\hline Input DC voltage & $V_{p}$ & $24 \mathrm{~V}$ (peak) \\
\hline Inductor & $\stackrel{p}{L_{p}}$ & $100 \mu \mathrm{H}$ \\
\hline Diode & $D_{p}$ & $\begin{array}{c}\mathrm{R}=1 \mathrm{~m} \Omega \\
V_{f}=0.8 \mathrm{~V} \\
R_{s}=500 \Omega \\
C_{s}=250 \mathrm{nF}\end{array}$ \\
\hline \multicolumn{3}{|c|}{ Components at the point of common coupling } \\
\hline Capacitor & $\mathrm{C}$ & $90 \mu \mathrm{F}$ \\
\hline Load & $\mathrm{R}$ & $100 \Omega$ \\
\hline
\end{tabular}
as eq (10)
TABLE I. SYSTEM PARAMETERS

$$
\hat{v}=\hat{v}_{r e f} \frac{1}{H(1+T)}+\hat{v}_{p} \frac{G_{v p}}{(1+T)}+\hat{v_{w}} \frac{G_{v w}}{(1+T)}
$$

Therefore, the output transfer functions for HRES is derived as given in (11) and (12) for solar and wind generators respectively. Furthermore, the bode-plot is shown in Figs. 7 and 8 .

$$
\begin{aligned}
& \frac{\hat{v}}{\hat{v}_{w}}=\frac{G_{v w}}{(1+T)}, \quad \text { when } \quad \hat{v}_{p}, \hat{v_{r e f}}=0 \\
& \frac{\hat{v}}{\hat{v}_{p}}=\frac{G_{v p}}{(1+T)}, \quad \text { when } \quad \hat{v}_{w}, \hat{v_{\text {ref }}}=0
\end{aligned}
$$




\section{Simulation Results}

The simulation of the proposed model is developed and verified using MATLAB/Simulink. A parallel integration of solar and wind generators are connected at the point of common coupling (PCC) with the load as depicted in Fig. 1 considering the following specifications provided in Table I.

The considered voltage variation is 4-24 V (peak) for solar and 19-27 V (rms) for wind turbine generation. The desired reference voltage required at the output is kept at $40 \mathrm{~V}$. The simulated and measured waveforms of output voltage $\left(V_{\text {out }}\right)$ and output current $\left(I_{\text {out }}\right)$ are shown in Fig. 9, from this it can be seen that the proposed controller design optimally maintains the voltage within permissible power quality requirements, irrespective of the voltage transience experienced due to solar irradiance and wind speed and hence satisfies the load requirement of the system.

\section{CONClusion}

In this paper, a parallel connection model of boost converter has been studied for multi-input renewable energy sources. Initially, the system was mathematically modelled taking small signal variations into consideration, and establishment of the respective current equation, voltage equation and characteristic transfer function of the system. Then the stability of the system was evaluated. Further, a model for parallel connection for different operating modes was simulated in MATLAB/Simulink environment. From the simulation results, it can be inferred that after some initial transience, ripples in the output voltage are minimised $( \pm 0.015 \mathrm{~V})$. Therefore, the stability of the system is maintained within the required permissible limits.

\section{ACKNOWLEDGMENT}

The authors would like to acknowledge the support provided by Aligarh Muslim University (AMU) and King Fahd University of Petroleum Minerals (KFUPM). Also we would like to acknowledge the funding support by the King Abdullah City for Atomic and Renewable Energy (K.A.CARE). In addition, the authors would like to acknowledge the support provided by Telecom Engineering and Substation Automation Department (TESAD), Saudi Electric Company (SEC).

\section{REFERENCES}

[1] Y. Yoldaş, A. Önen, S. Muyeen, A. V. Vasilakos, and İ. Alan, "Enhancing smart grid with microgrids: Challenges and opportunities," Renewable and Sustainable Energy Reviews, vol. 72, pp. 205-214, 2017.

[2] K. Bharath, M. M. Krishnan, and P. Kanakasabapathy, "A review on DC microgrid control techniques, applications and trends," International Journal of Renewable Energy Research (IJRER), vol. 9, no. 3, pp. 13281338, 2019.

[3] V. Khare, S. Nema, and P. Baredar, "Solar-wind hybrid renewable energy system: A review," Renewable and Sustainable Energy Reviews, vol. 58, pp. 23-33, 2016.

[4] L. Degroote, B. Renders, B. Meersman, and L. Vandevelde, "Influence of converter-connected distributed generation on distribution network losses," in Proc. of the Int. Conf. on Renewable Energies and Power Quality (ICREPQ'08), Santander, Spain, 2008.

[5] R. W. Wies, R. A. Johnson, A. N. Agrawal, and T. J. Chubb, "Simulink model for economic analysis and environmental impacts of a PV with diesel-battery system for remote villages," IEEE Transactions on Power Systems, vol. 20, no. 2, pp. 692-700, 2005.
[6] P. Kumar, R. K. Pachauri, and Y. K. Chuahan, "Duty ratio control schemes of DC-DC boost converter integrated with solar PV system," in 2015 International Conference on Energy Economics and Environment (ICEEE). IEEE, 2015, pp. 1-6.

[7] D. Delimustafic, J. Islambegovic, A. Aksamovic, and S. Masic, "Model of a hybrid renewable energy system: Control, supervision and energy distribution," in 2011 IEEE International Symposium on Industrial Electronics. IEEE, 2011, pp. 1081-1086.

[8] G. Tian, X. Ding, and J. Liu, "Study of control strategy for hybrid energy storage in wind-photovoltaic hybrid streetlight system," in 2011 IEEE International Workshop on Open-source Software for Scientific Computation. IEEE, 2011, pp. 77-81.

[9] Q. Mei, X. Zhen-Lin, and W.-Y. Wu, "A novel multi-port DC-DC converter for hybrid renewable energy distributed generation systems connected to power grid," in 2008 IEEE International Conference on Industrial Technology. IEEE, 2008, pp. 1-5.

[10] A. Agarwal, K. Deekshitha, S. Singh, and D. Fulwani, "Sliding mode control of a bidirectional DC/DC converter with constant power load," in 2015 IEEE First International Conference on DC Microgrids (ICDCM). IEEE, 2015, pp. 287-292.

[11] N. Lahari and H. V. K. Shetty, "Integration of grid connected PMG wind energy and solar energy systems using different control stratagies," in 2015 International Conference on Power and Advanced Control Engineering (ICPACE). IEEE, 2015, pp. 23-27.

[12] J. G. Priolkar and A. Gupta, "Management \& control of hybrid power system," in 2015 International Conference on Innovations in Information, Embedded and Communication Systems (ICIIECS). IEEE, 2015, pp. $1-6$.

[13] T.-C. Ou, W.-M. Lin, and C.-H. Huang, "A multi-input power converter for hybrid renewable energy generation system," in 2009 IEEE PES/IAS Conference on Sustainable Alternative Energy (SAE). IEEE, 2009, pp. $1-7$.

[14] K. P. Yalamanchili and M. Ferdowsi, "Review of multiple input DC-DC converters for electric and hybrid vehicles," in 2005 IEEE Vehicle Power and Propulsion Conference. IEEE, 2005, pp. 160-163.

[15] N. Smith and R. McCann, "Investigation of a multiple input converter for grid connected thermoelectric-photovoltaic hybrid system," in 2012 IEEE Green Technologies Conference. IEEE, 2012, pp. 1-5.

[16] H. Martínez García and J. Cosp Vilella, "Comparative aspects in control strategies for hybrid dc/dc converters," Renewable Energy and Power Quality Journal, vol. 1, no. 14, pp. 962-966, 2016.

[17] A. Abu-aisheh, "Design and analysis of solar/wind power electronics converters" Proc. of the Int. Conf. on Renewable Energies and Power Quality (ICREPQ'19), Tenerife, Spain," 2019.

[18] N. Moaddabi, M. Mahmoodi, and G. Gharehpetianm, "Control systems of distributed generation modules aggregated by cascaded boost converters," in Proc. of the International Conference on Renewable Energies and Power Quality, ICREPQ, vol. 7, 2007.

[19] M. N. Oliveira and D. F. R. L. R. Barbosa, "Proposal of an applicable ZVT quadratic boost converter topology in renewable energies" " Proc. of the Int. Conf. on Renewable Energies and Power Quality (ICREPQ'16), Madrid, Spain."

[20] A. Y. Lingzhi, B. C. Yu, C. R. Xuliang, and D. Z. Hao, "New mode transition of h-bridge bi-directional dc-dc converter in distributed generation system" "Proc. of the Int. Conf. on Renewable Energies and Power Quality (ICREPQ'17), Malaga, Spain."

[21] M. Kaliamoorthy, V. Rajasekaran, and G. PraveenRaj, "A novel single phase cascaded multilevel inverter for hybrid renewable energy sources," in 2015 International Conference on Advanced Computing and Communication Systems. IEEE, 2015, pp. 1-10.

[22] A. S. Samosir, N. Taufiq, and A. H. M. Yatim, "Simulation and implementation of interleaved boost dc-dc converter for fuel cell application," International Journal of Power Electronics and Drive Systems, vol. 1, no. 2, p. 168, 2011.

[23] N. Smith and R. McCann, "Analysis and simulation of a multiple input interleaved boost converter for renewable energy applications," in 2014 IEEE 36th International Telecommunications Energy Conference (INTELEC). IEEE, 2014, pp. 1-7. 